\title{
Hydrometry data rescue, a stake for the future
}

\author{
Frédéric Pons ${ }^{1, a}$, Christophe Laroche ${ }^{1}$, Céline Trmal ${ }^{1}$, Rachel Puechberty ${ }^{2}$, Martine Baillon ${ }^{2}$ \\ ${ }^{1}$ Cerema, Pole d'Activités Les Milles - Avenue Albert Einstein - CS 70499, 13593 Aix en Provence Cedex 3, France \\ ${ }^{2}$ SCHAPI, 42, avenue Gaspard Coriolis 31057 TOULOUSE Cedex 1, France
}

\begin{abstract}
The knowledge of past events and long-term series is a base to understand phenomena, analyze climate change and forecast future events. To increase long term series and their accuracy, NUNIEAU software, sort of "Digitizing Table", was developed and distributed freely since 2006 by Cerema. It is an international reference in tide gauge record, but has been improved to widespread its used for river and rainfall record. The SCHAPI (the French national service for hydrometeorology and support to flood forecasting) launched a tender to rescue the old data on rainfall and rivers available. Many improvements have been done to manage different types of rainfall charts. NUNIEAU was developed in French and is also available in English and Spanish version with collaboration of foreign institutes. Main challenge is not only to digitize old data but also assess the quality of digitized data. Protocol has been done to control the digitizing process and after to allows assessing the final quality of data.
\end{abstract}

\section{Context of hydro-meteorological data rescue and use of NUNIEAU}

The knowledge of past events and long-term series is a base to understand phenomena, analyze climate change and forecast future events.

To increase long-term series and their accuracy, NUNIEAU software was developed and distributed since 2006. NUNIEAU is a kind of virtual "Digitizer", with no paper size limit, initially specialized to convert tide gauge records $[1,2]$.

One of the main advantages is that you can check each parameter of the digitizing process and modify/correct it if necessary.

As a reminder, NUNIEAU process includes different steps:

- Scanning charts (e.g. image 200 dpi tif)

- Reference charts (one or more if needed referencing file is created by image)

- Digitalize charts (based on image and referencing file) with automatic cleaning tools

- Check series results
○ Visually
○ In table form
- With synthesis plots

- Concatenate all the data linked to each referencing file

NUNIEAU software uses a really simple process of image recognition. It just recovers a range in red, green and blue. Then, manual and automatic cleaning tools are used [1, 2, 3].

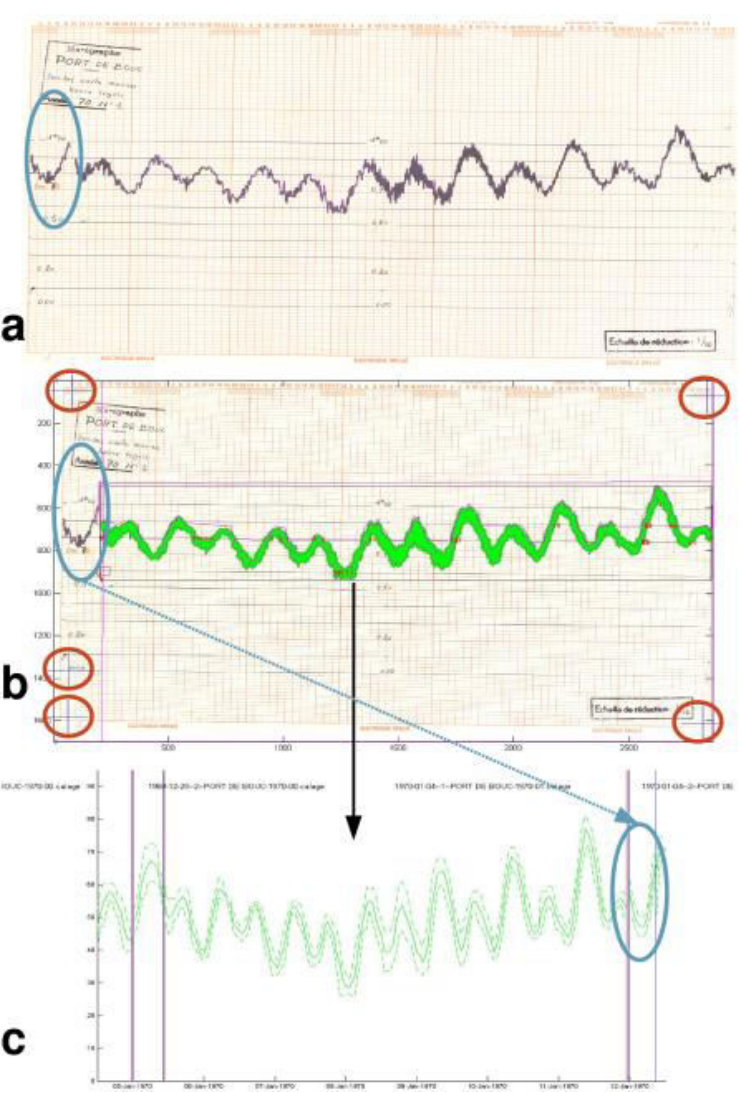

Figure 1. NUNIEAU process in Port de Bouc station (Mediterranean Sea) (a) Scan chart: in this case one week and a second little part surrounded in blue; (b) Referencing Chart in blue circle and recognition of signal in green pixels; (c) Result visualization referencing file by referencing file, the signal surrounded in blue in 1.a comes after in 1.c.

\footnotetext{
$\overline{{ }^{a} \text { Corresponding author: frederic.pons@cerema.fr }}$
} 


\subsection{The Beginning in Mediterranean Sea}

The first rescue was done after 2004 for sea level series in the Gulf of Lion (French western part of Mediterranean sea). Only a dozen of numerical years was available in this area before this work. This rescue had two objectives.

The first one was to capitalize knowledge of past events and try to give indication about maximum level and statistic levels [3, 4]. About 150 cumulate years of data were rescued in sea and lagoons areas. Technical reports were provided to give an overview of data quality. We estimate if series are available for analyze of:

- $\quad$ historical extreme events,

- $\quad$ sea level statistics

- $\quad$ sea level change related to climate change.

The second objective was to correlate these series with long-term climate change as weather regimes [5].

\subsection{Enlargement for other French data type}

Data rescue is needed not only in Mediterranean Sea but also in the other coasts of French areas. The French national hydrographic institute (SHOM) was interested to use this software instead of being dependant of a digitizer table.

Some improvements were made to take account of macro-tidal sea particularity (Figure 2).

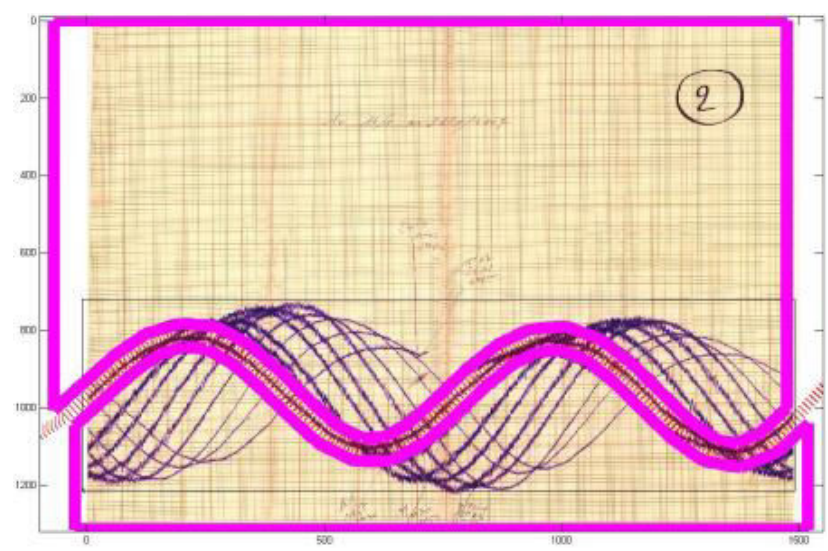

Figure 2. Port-Tudy Harbors in Atlantic Ocean, there were 10 days on the same image. The duration in $\mathrm{x}$ is one day. Magenta polyline is created with predicted tide to recover only day by day.

As in the Mediterranean Sea, the objective of this rescue was the capitalization of old data to know extreme events and study effects of climate change [6]. But NUNIEAU offers the possibility to work very precisely depending on paper size and scan precision. It allows other uses. For example, SHOM was involved in a tsunami study project after the Sumatra 2004 tsunami. NUNIEAU enabled to rescue tsunami waves along French coasts. Objectives were to correlate seisms and height waves $[7,8]$.

At the same time, SCHAPI (French national service for hydrometeorology and support to flood forecasting) ordered the development of a NUNEAU river module.
There were some benchmarks in some forecasting service. But few services spent time to do the digitalization and this module was not well tested. The main improvement was the refolding effect (Figure 3) which occurs during extreme flows.

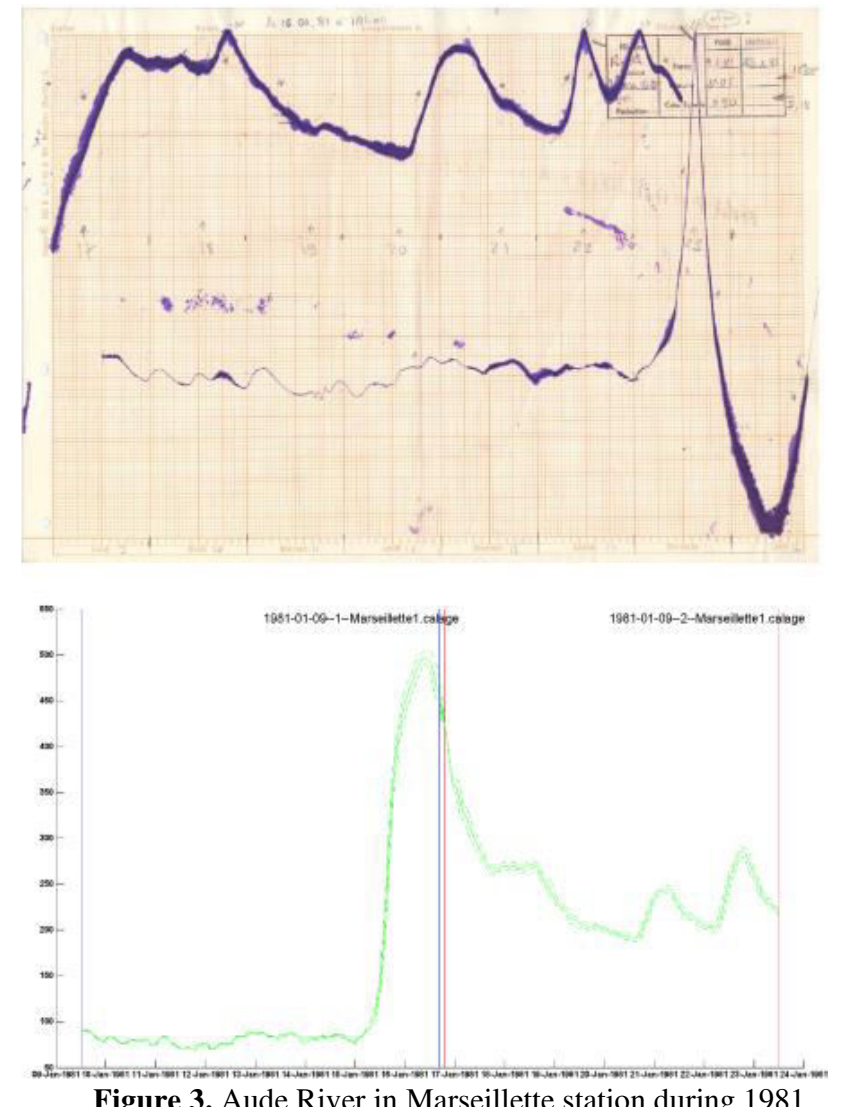

Figure 3. Aude River in Marseillette station during 1981 floods. There are two signals, each about one week. We can notice there are refolding effects on the two signals. The plot below shows the treatment of the original data.

Regional service of French Guyana wanted to improve their knowledge of rainfall and we helped them to manage rainfall chart record in NUNIEAU. Technical results were promising. But only developers used rain module (Figure 4). 


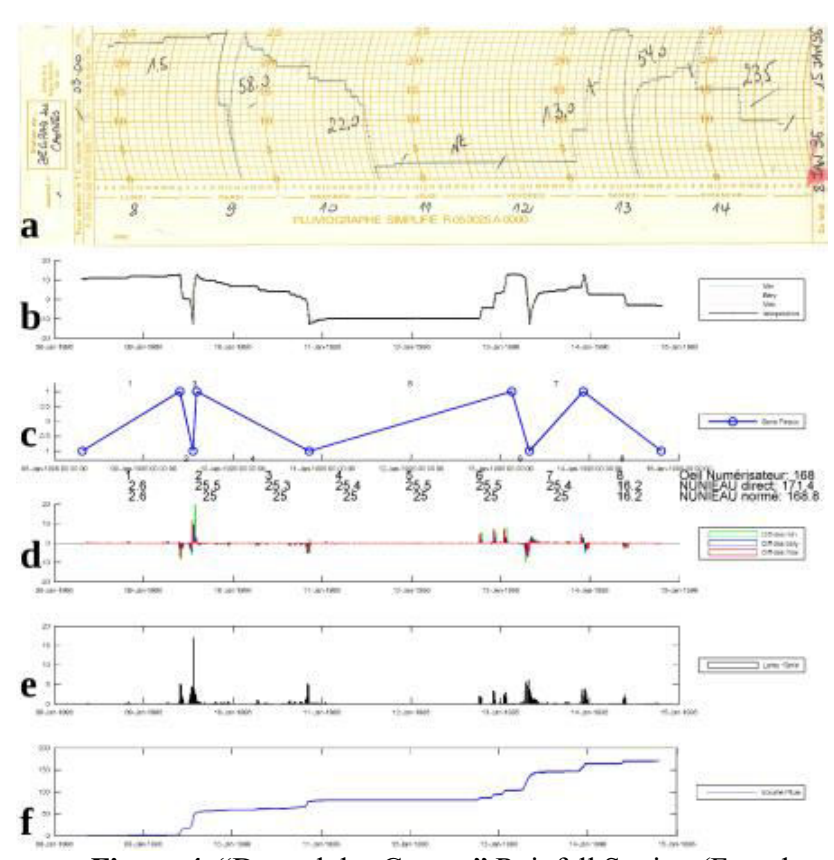

Figure 4. "Degrad des Cannes" Rainfall Station (French Guyana); (a) one week rainfall chart; (b,c,d,e,f) NUNIEAU treatment; (b) Recognition of signal; (c) Automatic recognition of refolding effects, $(\mathrm{d}, \mathrm{e})$ Rainfall Histogram at the choose step time, 15 minutes in this case; (f) Cumulative rainfall hyetograph

Rainfall module is quite complex. Y-axis is curved. The signal is a cumulated rainfall with refolding effects. These effects need to be identified (Figure 4.c). Then, rainfall histogram is calculated by difference of value during a time step.

A test of rainfall module was run with French Meteorological Institute (Météo France). They have also developed their own tool named DIGITALISE and based on digitizer table. Some conclusions of Météo France in one of their ANR EXTRAFLO reports are:

- Results are near the same between the two approaches

- $\quad$ Differences are visible for very short time step (6 or 15 minutes)

- DIGITALISE can lower peaks and NUNIEAU can increase peaks

- DIGITALISE is quicker for rain analysis but need to be used by confirmed users with a good knowledge of rainfall measurement

- NUNIEAU, more complex in parameters, is more generic (a lot of record can be managed). It could be easily deployed, without material, particularly for tenders.

In this ANR EXTRAFLO project, one objective was the best assessment of extreme rain events [9] and a part of the project was the rainfall data rescue.

\subsection{Foreign experience}

Data rescue is anything but simple. It needs time despite the fact that NUNIEAU or other types of tools are available. Moreover, data rescue is often less considered than working on numerical models even if data are the base for a good calibration and understanding.

Few people work on these data. Even if a lot of archives are known, few institutions decide to launch huge rescue works.

For NUNIEAU software, Survey of India (SOI) wanted to use it. SOI translate a part of the software in English for its internal needs.

Some trainees used NUNIEAU rain module in Burkina Faso and Chile in industrial conditions. This means NUNIEAU can be used with few support, by people not involved in the development and for producing long data series in different types of chart format. The two projects aims to produce rainfall Intensity-Duration-Frequency $[10,11]$. NUNIEAU had to be adapted to Chile rain gauge type (Figure 5). Chile rainfall chart use an orthogonal axes with no curved Yaxis. It was also an opportunity to compare with other tools [11], and the conclusions were:

- Software exist but are not available

- Software are linked to a type of rainfall chart

- Software are not free

- Software are program prototypes

Figure 5. Rainfall Chile example, grids are Cartesian axes instead of most of chart as Figure 3.a.

Some software [12, 13] seem to use more complex image treatment to digitalize rainfall charts. Nevertheless, in some case, they have some problem in recognition. DIGITALISE and NUNIEAU have the same type of problem for rainfall particularly for extreme rainfall. A lot of time, problems come from record bugs on the chart and not on software recognition (come back of the stylus). One of the particularities of NUNIEAU, coming from the sea application is to provide at each time a value of minimum, maximum and barycenter of all the graphs. This particularity is really important to manage a lot of waves for sea and also river. For rainfall chart, barycenter is used and at each refolding, we manage minimum and maximum to conserve rain.

Even if some problems exist in the use of NUNIEAU [14], the work done by Cerema, other French and foreign institutions enable to consider NUNIEAU as "the only publically available software for digitizing tide gauge chart" [15]. With the rainfall conclusion [11], this sentence could be extended to sea, lagoon, river and rainfall gauge.

\section{Needs of French flood forecasting services for data rescue}

The French flood forecasting services and SCHAPI have to forecast each days the levels of French rivers. Rainfall and rivers observations represent the main data for the monitoring tools and flood forecasting. Since 1990, databases have been implemented to manage and collect data. Some old series are already present in these 
database but they are very few. Usually, the length of numerical archives is limited to the past 20-30 years. Nevertheless, a lot of information is available in paper format with paper table or charts.

Numerous last dramatic floods in France appear to be exceptional regarding the short numerical series. But, historical researches enable often to moderate some comments.

Moreover, old data are sometimes in a poor state of preservation and could disappear with different relocations of institutions.

For theses elements, SCHAPI has decided to propose the rescue of theses data with a national tender with order form. This tender needs the use of:

- Simple spreadsheet software for old written tables (Table 1)

- NUNIEAU for all the sea, estuary, river and rainfall charts.

The old paper data come principally from the second half of 20 century but some of them begin around 1850 .

For old written tables (Table 1), the tender is only a manual digitalization. Table 1 shows handwritten values. In many cases, several operators can write on the same table. So semi-automatic recognition does not seem to be cost effective. But this type of recognition could be a solution in case of old table printed as hydrological yearbooks of the "Société Hydrotechnique de France" [16]. In this project, internal control process and results checking with meta-data are an important part of this rescue [16].

For old charts, the number to be rescue is not really known. Estimation could be more than 200-500 years of data in each flood forecasting service, or almost 400010000 years of old information.

An important work to do is to know which are the most important series to rescue. The objective is to fill geographic lacks in the French territories. For rainfall, Météo France climatological database (BDCLIM) must be used for this comparison. For rivers, and estuary, river database HYDRO2 and sea database REFMAR will be used.

But this work has also to be done regarding the final quality available. For example, what kind of metadata is available, what kind of checking is possible? The next part shows the different process and protocol in NUNIEAU to assess the final quality of digitized data.

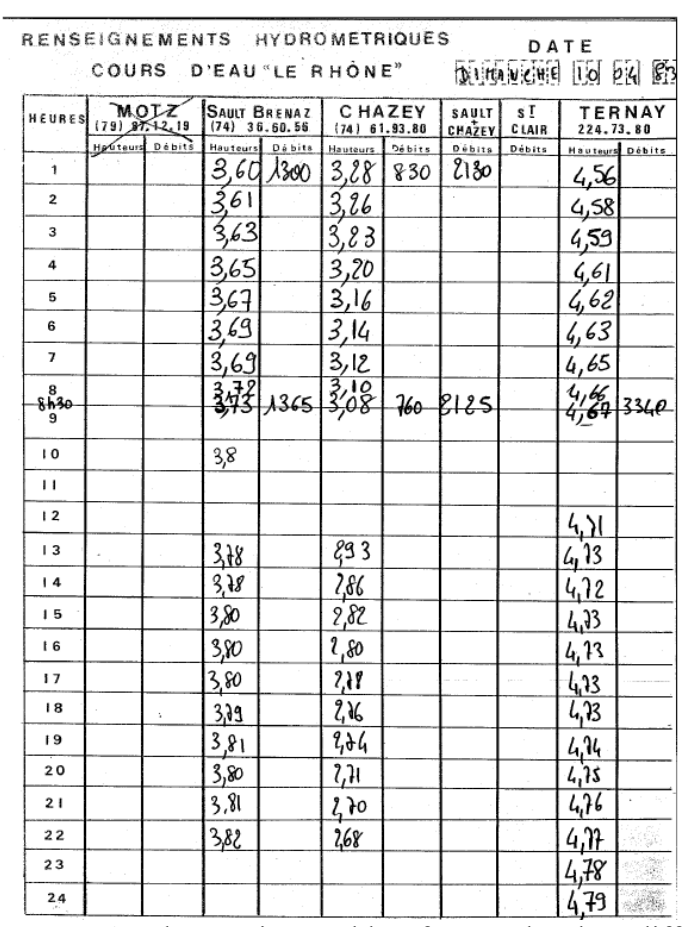

Table 1. Rhone River, table of water level at different station on day.

\section{NUNIEAU protocol}

Usually, the rescue of old data is leaded by research needs, mainly on studies concerning climate change. People involved in these rescues (doctoral student, trainee) want to have a very accurate result.

The use of the tender brings people to really study in detail the entrusted mission. We need to define what companies have to do, and also what companies cannot do. Sometimes, we can work very well but, at the end, the series can be rejected because of problem on the gauge mechanism or use.

We have also some requests to convert NUNIEAU in a web application for an interactive project on sea level. The aim is to involve volunteer citizens to collaborate to the old data rescue.

The needs for the following operation, assessing accuracy of the process of digitalization and assessing accuracy of the final series are a challenge for tender or interactive project. It is also very important for communication around accuracy of climate change survey.

So we propose to distinguish two kinds of checking:

- The validation of digitizing process. We need to have the same value after digitizing process than read on the paper. This digitizing step can be perfect but the recording can still have some problems of time or altimetry-bias.

- The validation of the final data. This validation needs meta-data. These meta-data are sometimes not only given by signal on charts but also in other documents (log book...). 
These types of meta-data are:

- Date and time of laying the chart,

- Coast-to-wide-during installation, rain accumulation measured in parallel,

- Date and time of withdrawal of the chart,

○ Coast-to-wide during the withdrawal.

People in charge of digitizing process must insure the first validation. For the second validation, people in charge of digitizing process have to fill the meta-data. But only expert people can be in charge of the accuracy conclusion on final series.

We focus now on the available checking in NUNIEAU. These checking enable to have a quick overview on work quality and to distinguish coarse error. At the first step, operators can sometimes make errors in NUNIEAU process. We have sometimes 5 to $10 \%$ of errors ( 1 bad referencing point). This value could seem very important. But, for other data provides by manual rescue/software, it is the same extend! Repetitive tasks lead to these kinds of errors.

So, we have to create a control process to cope with these problems and other possible errors linked to NUNIEAU digitizing process or error in material recording. The list below shows what can be done in NUNIEAU as check:

- Visual checking chart by chart

- Checking the cleaning on each graph is correct

- Comparing the continuity of signal on consecutive images (Figure 1.c)

- More global checks described in following paragraphs

\subsection{Report of digitalization and digitalization sheet}

Each image can be related to one or more referencing file (Figure 1). In the case of 30 years series with weekly graphs, NUNIEAU manages about 1500 referencing files. It is not possible to check each one of them so we need to combine all the referencing files.

A procedure compacts all the referencing files in a table with a lot of referencing information.

This table can be visualized in spreadsheet software and a lot of little check can be done:

- Value of Time and altimetry continuity of signal of image $n$ with image $n-1$ and $n+1$

- Comparison between value and time of image $n$ with meta-data of image $n$.

A digitizing sheet is also provided (Figure 6).

- The first plot shows if the support is in color or in gray color. In this case, main charts were in colors. Four years have been processed with photocopies in black and white (gray color). Color charts were lost.

- The second plot shows the number of referencing files by image. In this case most of the images have only one referencing file and some of them two. Figure 1 and Figure 3, have 2 signals. Figure 4 and Figure 5 have one signal. Figure 2 has about 10 signals by chart and thus 10 referencing files by image!

- The third plot shows the choice of range of color in RGB. We can notice if the recognition of color was quite difficult and if colors are homogeneous.

- The fourth plot shows ratio between the length and the width of the grids. The value is not important (depending on dpi scan). The important point is steadiness. Each change in shape of plot could be some scale changes during the period of time. In this case, we see two shapes. In fact, two different maregraphs were implemented at the beginning and at the end.

- $\quad$ The fifth plot shows the possible time shift you can integrate in referencing files. In most cases, it is better to have something at zero. Sometimes, it can be better to add or minor with some hours to be continue with the signal before and/or after. A lot of papers were manually placed and some human artifacts of shifts are presents and can be moved.

- The last plot is the same than the previous one but for altimetry reference.

Fiche Numérisation: 013200---GRAU-DE-LA-DENT-2015-06-17

Périodes enregistrées: 32.6 années, Support Numérique Niveau de Gris ou couleur Rouge-Vert-Bleu
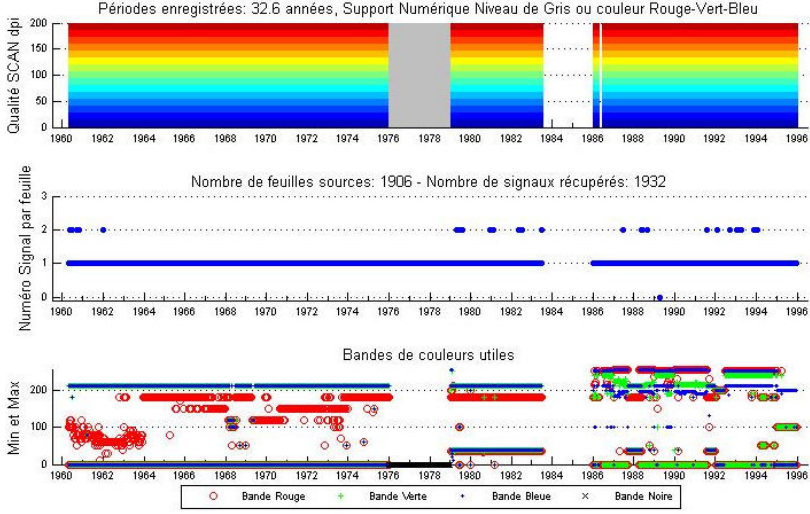

Changements d'échelle, de type de format ou de référence verticale

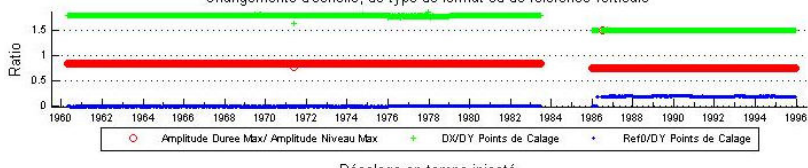

Décalage en temps injecté

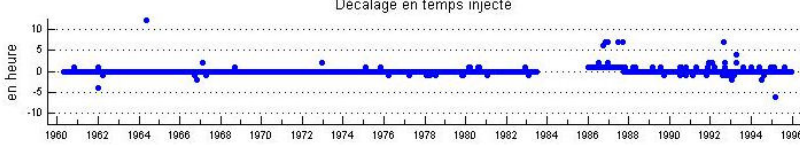

Décalage en hauteur injecté

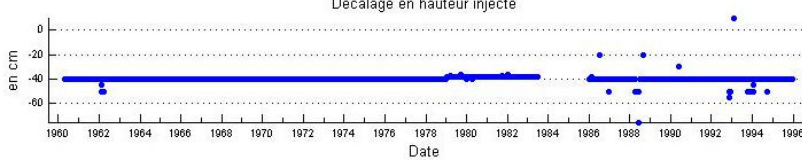

Figure 6. Digitizing sheet (description in text) 
The objective of the digitizing sheet is to have flat graphs. Sometimes, values can be different of the main tendency. It is perhaps normal. But an expert people have to check and validate. In data rescue, you have to combine a lot of human or instrumental mistakes. For example, we managed sometimes a sheet turned upside down!

\subsection{Geometric sheets}

In NUNIEAU grid referencing, we need to create some reference points ( 5 red circles in Figure 1.b). 5 points are required in case of sea and river charts,. 6 points for most rainfall charts (Figure 3.a), only 4 for some other kind of rainfall charts (Figure 5)

Automatic sheets (Figure 7) are created to visualize possible geometry mistakes. Most of the time, all the curves have to be flat. It is the case for Anduze rainfall chart, where the range in $\mathrm{y}$-axis is short.
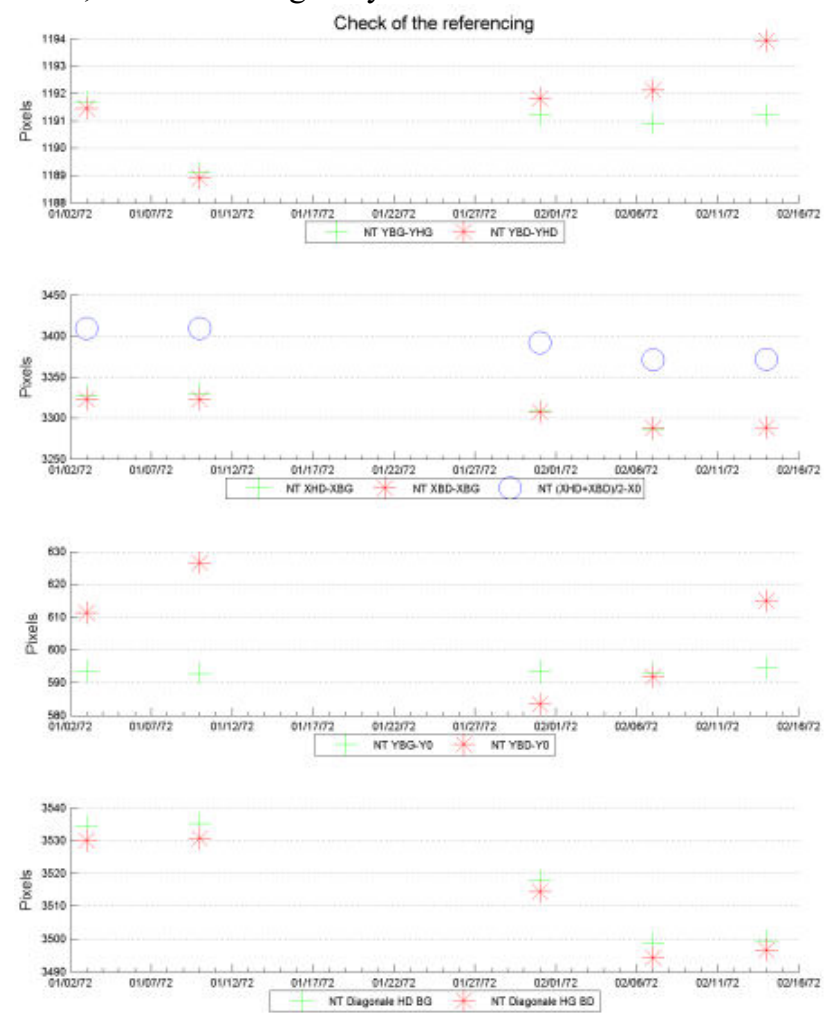

Figure 7. Geometric check, the plots shows up to down first, the width, the height, the reference, and the diagonal length between all the referencing points.

\subsection{Continuity sheets}

Another possible check allowed by NUNIEAU, not found in other software $[12,13]$, is the continuity between results of each referencing file and matching with metadata.

For the continuity, it is possible to have a visual control (Figure 1.c or Figure 3). It is also possible to work on the digitizing report in spreadsheet table.

In NUNIEAU, we figure out this value in plots (Figure 9). Even if the continuity is visually insured, it is good but not enough to control time and altimetry bias.
The best qualification is work with meta-data explained in beginning of chapter 3 .

The meta-data presented in Figure 8 is a parallel control of the measurement. For example in figure 8.a the time is given and 3 values (orange) are provided as an external control of the cumulative rainfall. In Figure 8.b, time is given when laying and withdrawal the chart. Altimetry value is given with a parallel reference point measure. This measure is attached to a local leveling-base height reference. These meta-data play a key role in the possibility to give accuracy to final series.

Unfortunately, the meta-data presented in Figure 8 are often not present on the chart record. They can be present in some logbooks. Others precautions have to be taken because in some case it is not a parallel control but just a reading on the chart. It is very difficult to be aware of this kind of problem.

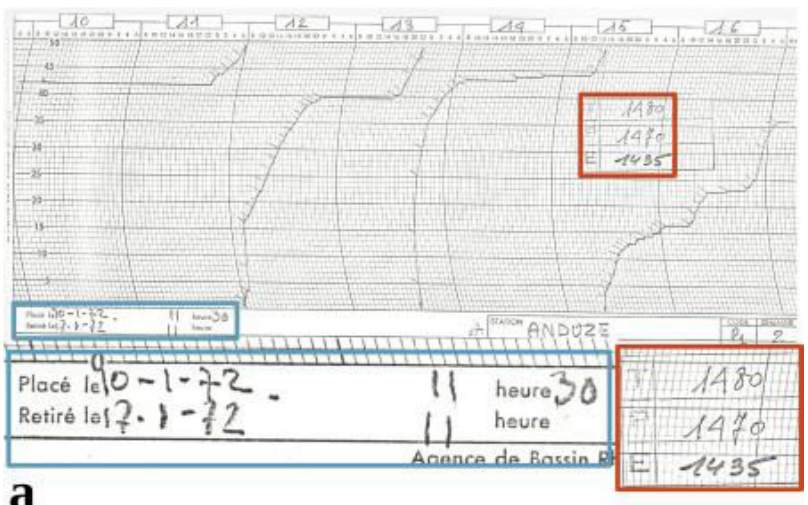

a

b

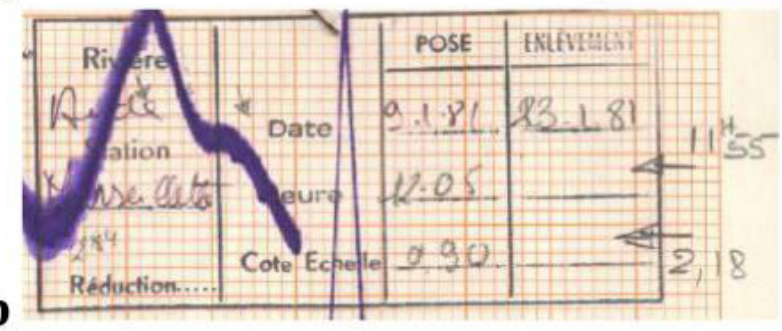

Figure 8. Example of meta-data; (a) Anduze rainfall chart with the date (blue rectangle) and with a parallel control (orange comparison); (b) meta-data time and height of Aude river attached to Figure 3.

As well as continuity, we can compare the value of NUNIEAU with meta-data on digitizing report. But NUNIEAU proposes to see these results in plots (Figure 9).

Figure 9.a and 9.b allow comparing the time, at installation and withdrawal between NUNIEAU digitized data and meta-data. In this case, time difference could be more than 60 minutes.

Figure 9.c and 9.d are not presented because in the case of rainfall chart, the compare value is the cumulative rainfall during the period of the chart. This will be explained in the next paragraph. If comparison is possible and meta-data available, we can compare height, at installation and withdrawal between NUNIEAU digitized data and meta-data. 
Figure 9.e and 9.f show the continuity between all the referencing files results in time (Figure 9.e) and in height (Figure 9.f).

Often, visualizing these kinds of plots enable to be aware with the precision of old data.

Some thresholds limit the scale of difference in time and height (for example $+/-300$ minutes and $+/-20 \mathrm{~cm}$ ). It is necessary to a good analysis of plots. If values are out of this range, a txt bug file is provided giving referencing files with problems.

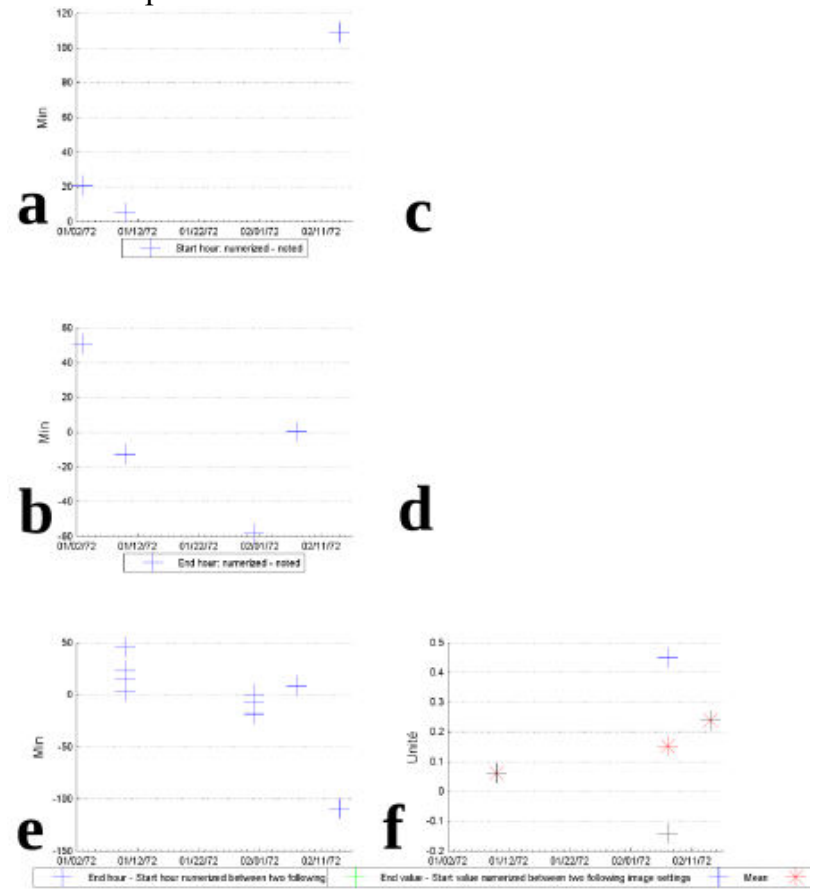

Figure 9. Plots to compare continuity and meta-data

\subsection{Rainfall charts particularities}

For rainfall charts, validation is less easy. The automatic refolding effects can be difficult, mainly during extreme rainfall. Sometimes the stylus goes up and down too quickly.

So we need two kinds of validation.

The first one is a comparison between the cumulative rainfall present on the paper and the cumulative rainfall digitized with NUNIEAU. In NUNIEAU, we have a time step to recognize signal. The difficulty is that in some cases, results are good for 6 minutes step and not for 60 minutes. Sometimes, it is the other way around. In the case of Figure 4.a, the operator has to note in referencing data the read value, namely $2 \mathrm{~cm}$ plus 6 refolding effects of $25 \mathrm{~cm}$ and $16 \mathrm{~cm}$. The cumulated value is 168. If NUNIEAU recognizes a refolding effect, it normalizes the value at 25, in Figure 4, some values are more $25.5 \ldots$ but we consider as absolute the specification of the instrumentation. The 168 value is written on Figure $4 \mathrm{c} / \mathrm{d}$ and used in the NUNIEAU treatment. Below the read value of operator is 168 , the direct value digitized with NUNIEAU is 171.4 and after normalization, it is 168.8 .
Each operator can do the checking during process. But some general plots are welcome to simplify the process and expert people to check the works done by others (tender, operators...). The Figure 10 shows an example on Anduze case. This case is an other rain format. The recording is only going up, there is no recording when stylus goes down. In this case, the operators have to enter a value for each referencing file. An uncertainty of $5 \%$ is accepted, and, the referencing file allows an ex-post control. If some points are far away, the cleaning process and the time step have to be controlled.

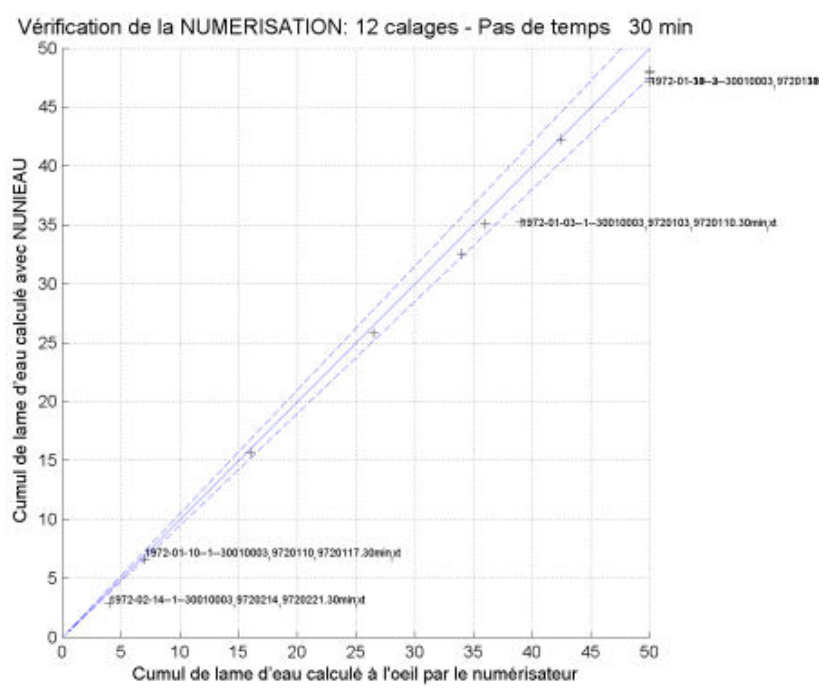

Figure 10. Check of cumulative rainfall between cumulative rainfall read and calculate quickly by operator (x-axis) and the cumulative rainfall calculated with NUNIEAU (y-axis).

The second comparison needs meta-data. Figure 8.a; shows parallel cumulative rainfall values. All the referencing files correlated to a parallel cumulative value must be cumulate.

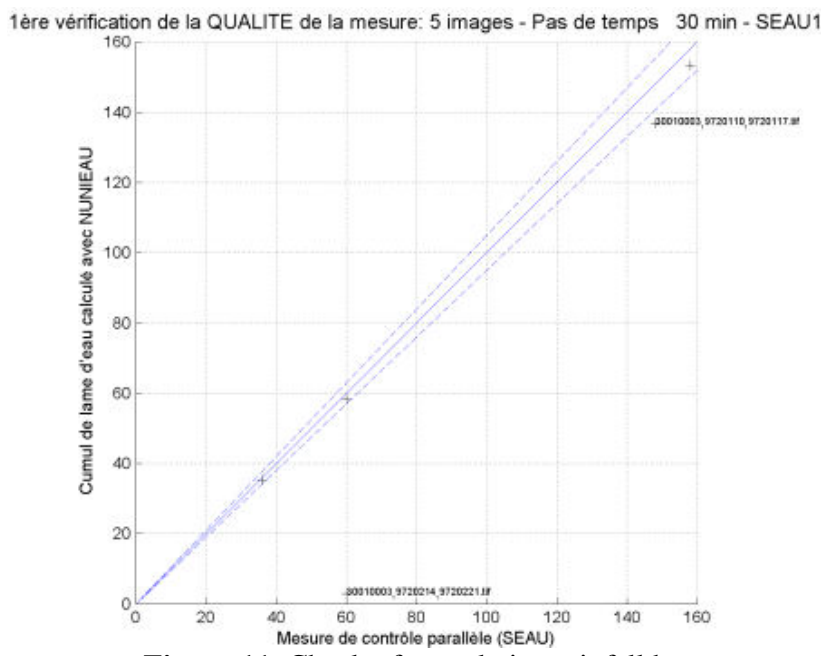

Figure 11. Check of cumulative rainfall between cumulative rainfall with a parallel control (x-axis) and the cumulative rainfall calculated with NUNIEAU (y-axis). 
In the case of Anduze station, we have 12 referencing file (Figure 10) and only 5 images treated (Figure 11) so some images have more than 1 referencing file. These plots show near $\mathrm{x}$-axis and between 60 and 100 values a point out of the accepted range in blue. Explanation of its outlet is that the last chart has a problem of recording during the week. Stylus is blocked. Therefore, digitizing value is less than parallel control rainfall.

\section{Discussions}

Data rescue is a challenge to a best understanding but need to qualify data. NUNIEAU process is very widespread for hydrometric data and for meteorological data. Perhaps, the recognition process is less developed than literature [12, 13] but robust and well adapted to manage a lot of kind of thematic charts and their state of conservation.

After the digitizing validation process in NUNIEAU, the work is not finished. Expert people has to analyze final results and in each thematic subject to propose control tools.

For sea level, solutions exist and series can be validate individually with tide analysis [2]. A very easy way is to analyze the steadiness of tide harmonics. For example, you can calculate tide harmonic amplitude with a rolling window of 2 months each week. If harmonic amplitudes and phases are steady, it has a very good validity.

For rivers, the height is measured and not the discharge, which is usually preferred. A hard work, as for ongoing measurement is to have a good rating curve in relation with the different period of the series. High levels can also be an information but series managers must think about the final accuracy of series depending on meta-data, the modification of local cross sections and time-spent in this process. The accuracy of the series can been approach with the water level shape between stations of the same watershed. NUNIEAU enable to work on several stations in the same time and compare visually river levels during a flood event. The check could be with the integration of series in operational hydrological models to see if hydrological behaviors are logical.

Sea level is a direct measure; river is less direct with the rating curve. Rainfall is also a direct measure. But, the accuracy is very hard to insure. International organisms and Météo France have done a lot of works on this subject. But different kinds of pluviograph instrument in the same place do not give the same results. And with current measurement, difference between local pluviograph and meteorological radar are anything but negligible. The cumulative value on day, week and year can enable to eliminate significant mistakes. But despite the fact we can use in NUNIEAU or other a 6 minutes step, caution should be exercised when considering such values. Perhaps, a short step time is useful for statistic analysis. Nevertheless, using it for modeling a past event could lead to shift in hydrological behavior.
All the precaution done here must not stop the operation of data rescue. Data rescue is a stake for the future. With archives, we can bank quickly 10,20 or 50 years of data without waiting 2025,2035 or 2065 . So, it is a challenge to propose long series with most possible accuracy. And this accuracy is a key to enable best studies, for example about climate change.

We need to be very professional because results of very old series are after used in order to take regulatory value, especially for sea level rise. Extreme flood events are also the reference for urban rules defined in local French flood prevention plan.

This is a sensitive subject and scientists and technicians have to ensure the best control system available to work without controversy.

\section{Acknowledgements}

We acknowledge structures, which funded software development or training and give feedbacks (DREAL Languedoc-Roussillon, SCHAPI, SHOM, COFEYFABRICOM Belgium GDF-Suez).

We also acknowledge people and structures which give contributions or feedbacks to NUNIEAU software, LEGOS, La Rochelle University, DREAL Ile de France, Survey of India, Météo France, "2iE Institut International d'Ingenierie" of Ouagadoudou, Conception University, GBInfographie SARL and François Helloco consultant.

\section{References}

1. Ullmann A., Pons F. and Moron. (2005). Tool Kit Helps Digitize Tide Gauge Records. Eos Transactions American Geophysical Union, 86(38). DOI:10.1029/2005EO380004

2. Pons F. (2008). Améliorations récentes apportées au logiciel NUNIEAU pour la numérisation des marégrammes papiers. Xèmes Journées Nationales Génie Côtier - Génie Civil, Sophia-Antipolis, Nice

3. Pons F. (2008). Utilisation des données anciennes pour la connaissance des risques de submersions marines. Colloque SHF-: Nouvelles approches sur les risques côtiers, Paris

4. Pons F., Trmal C.and Vanroye C. (2010). Analysis of coastal water levels in Gulf of Lions. Storm Surges Congress, Hamburg

5. Ullmann A., Moron V. (2007). Weather regimes and sea surge variations over the Gulf of Lions (French Mediterranean coast) during the 20th century, International Journal of Climatology, Vol 28, Issue 2, 191-171

6. Gouriou T. (2012). Évolution des composantes du niveau marin à partir d'observation de marégraphie effectuées depuis la fin du $18^{\text {ème }}$ siècle en CharenteMaritime, Thèse en océanographie Physique, Université de la Rochelle

7. Labbé M., Donnadieu C., Daubord and Hebert H. (2012). Refined numerical modeling of the 1979 tsunami in Nice (French Riviera): Comparison with coastal data, Journal of Geophysical Research, Vol 117, Issue F1 
8. Allgeyer S., Daubord C., Hébert H., Loevenbruck, Schindelé F. and Madariaga R. (2013). Could a 1755-Like Tsunami Reach the French Atlantic Coastline? Constraints from Twentieth century Observations and Numerical Modeling, Pure Appl. Geopohys, Vol 170, 1415-1431

9. Soubeyroux J-M., Borchi F., Colombon N., Baillon M., Veysseire J-M., Jourdain S., Gibelin A-L. and Auffray A. (2011), Valorisation de la digitalisation des series pluviographiques anciennes. Apport pour l'estimation des précipitations extrêmes en France, La Houille Blanche, Vol 5, 12-19

10. Paturel J-E., Traoré M., Pons F., Karambiri H., Laroche C. and Garane A J. (2013). Vers l'obtention de nouvelles courbes IDF en Afrique de l'Ouest et Centrale-application du logiciel NUNIEAU-pluie et premiers résultats à la station de Ouagadougou au Burkina Faso, Tème édition des Journées Scientifiques 2iE, Ougadougou

11. Bozonnet A. (2014). Extraction de données hydrologiques en vue de la construction de nouvelles courbes IDF pour la ville de Concepción, Rapport de stage Pratique de Ingénierie, Universidad de Conception et ENGEES

12. Roberto Deidda R., MascaroG., Piga E., Querzoli G. (2007), An automatic system for rainfall signal recognition from tipping bucket gage strip charts, Journal of Hydrology, Vol 333, 400-412

13. Jaklič A., Šajn L., Derganc G. and Peer P.(2016). Automatic digitization of pluviograph strip charts, Meteorological Applications, Vol 23, Issue 1, 57-64

14. Murdya J., Orforda J. and Bell J. (2015). Maintaining legacy data: Saving Belfast Harbour (UK) tide-gauge data (1901-2010), GeoResJ, Rescuing Legacy Data for Future Science, Vol. 6, 65-73

15. Bradshaw E., Rickards L. and Aarup T. (2015). Sea level data archaeology and the Global Sea Level Observing System (GLOSS), GeoResJ, Rescuing Legacy Data for Future Science, Vol. 6, 9-16

16. Le Gros C., Sauquet E., Lang M., Achard A-L, Leblois E. and Biton B. (2015) Les annuaires hydrologiques de la Société hydrotechnique de France : une source d'information patrimoniale pour la connaissance de l'hydrologie en France, La Houille Blanche, Vol 4, 66-77 